\title{
ARID1A: THE GOOD, THE BAD AND THE UGLY
}

Beth Israel Deaconess

Medical Center

gigir HARVARD MEDICAL SCHOOL TEACHING HOSPITAL
PEINADO P1,2, ANDRADES A ${ }^{1,2}$, SANJUAN-HIDALGO J2 , HASWELL JR ${ }^{3}$, ALVAREZ-PEREZ JC ${ }^{1,2}$, SLACK FJ3,4 AND MEDINA PP1,2*

Department of Biochemistry and Molecular Biology I, Faculty of Sciences. University of Granada, Spain

${ }^{2}$ Centre for Genomics and Oncological Research (GENYO), Granada, Spain. *Corresponding author: pedro.medina@genyo.es

'Department of Pathology, Cancer Center, Beth Israel Deaconess Medical Center, Boston, MA, USA. ${ }^{4}$ Harvard Initiative for RNA Medicine, Boston, MA, USA.

\section{YGenyo}

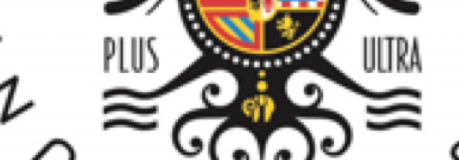

TA PE ANDALUCIA DE GENÓMICA INVESTIGACIÓN ONCOLÓGICA

\section{BACKGROUND AND OBJECTIVES}

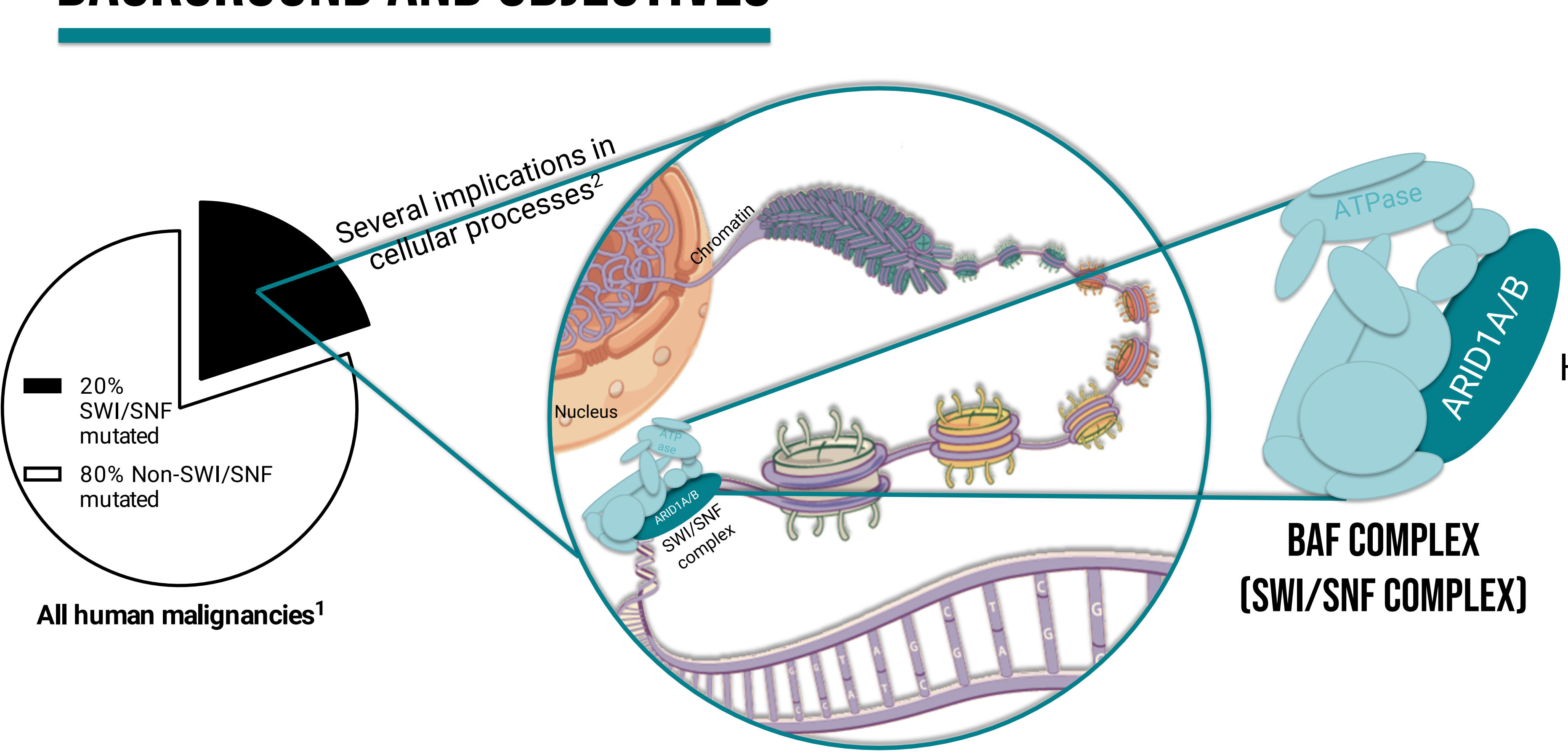

Gastric Carcinoma Bladder Carcinoma

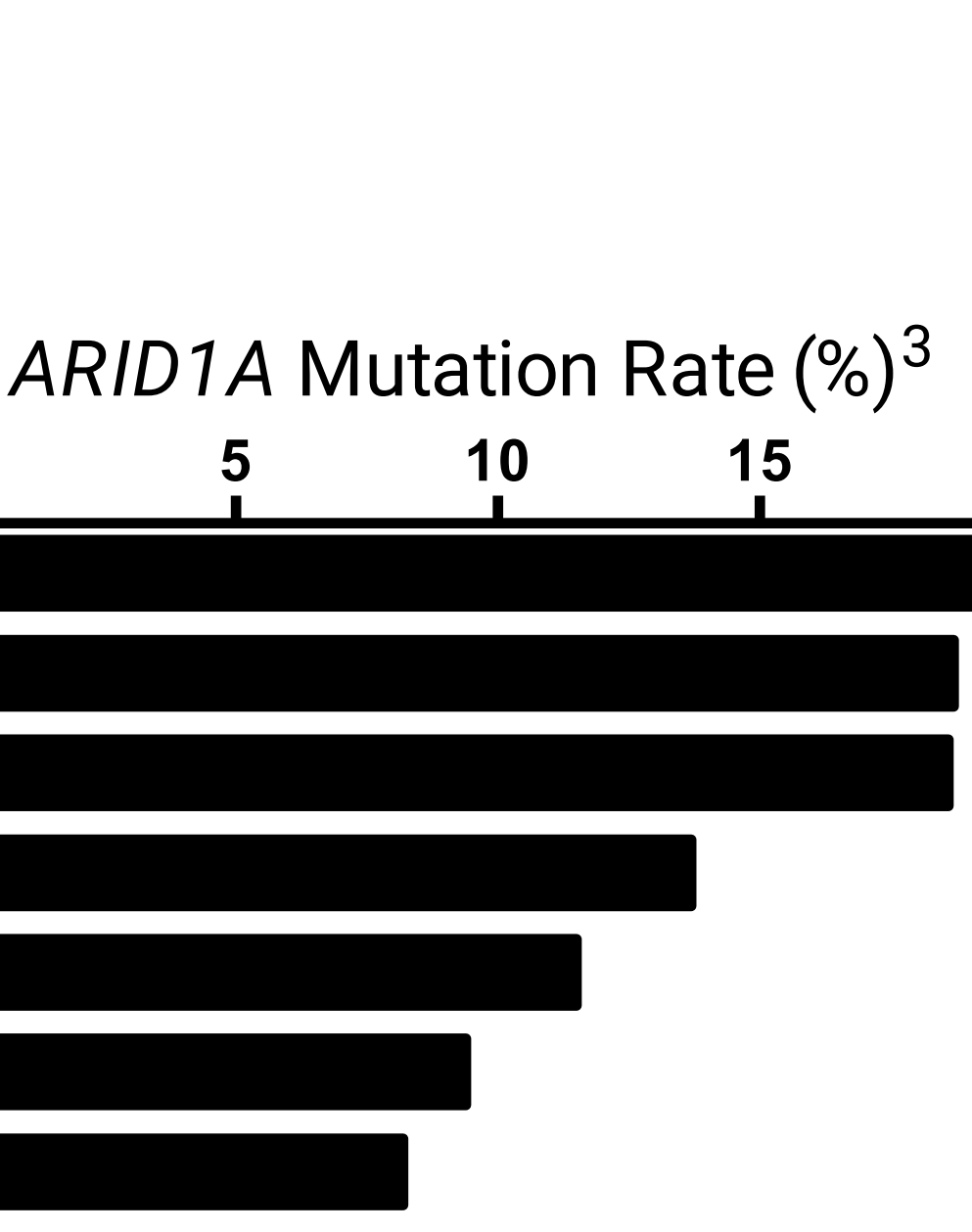

Colorrectal Cance Lung Cancer

Mostly, inactivating mutations ${ }^{3}$

Bona Fide Tumor Suppressor Gene

TCGA data: ARID1A with a $6.5 \%$ mutation rate $\leftarrow$ $A R I D 1 A$ is defined as a driver cancer gene in $\operatorname{LUAD}^{8} \leftarrow$ Few'experimental evidences of its tumor suppresor role $\leftarrow$

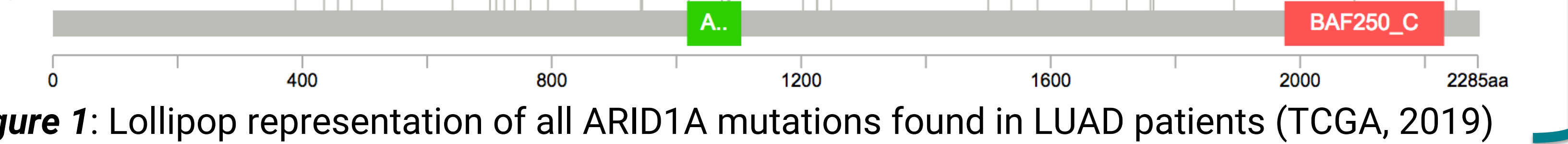

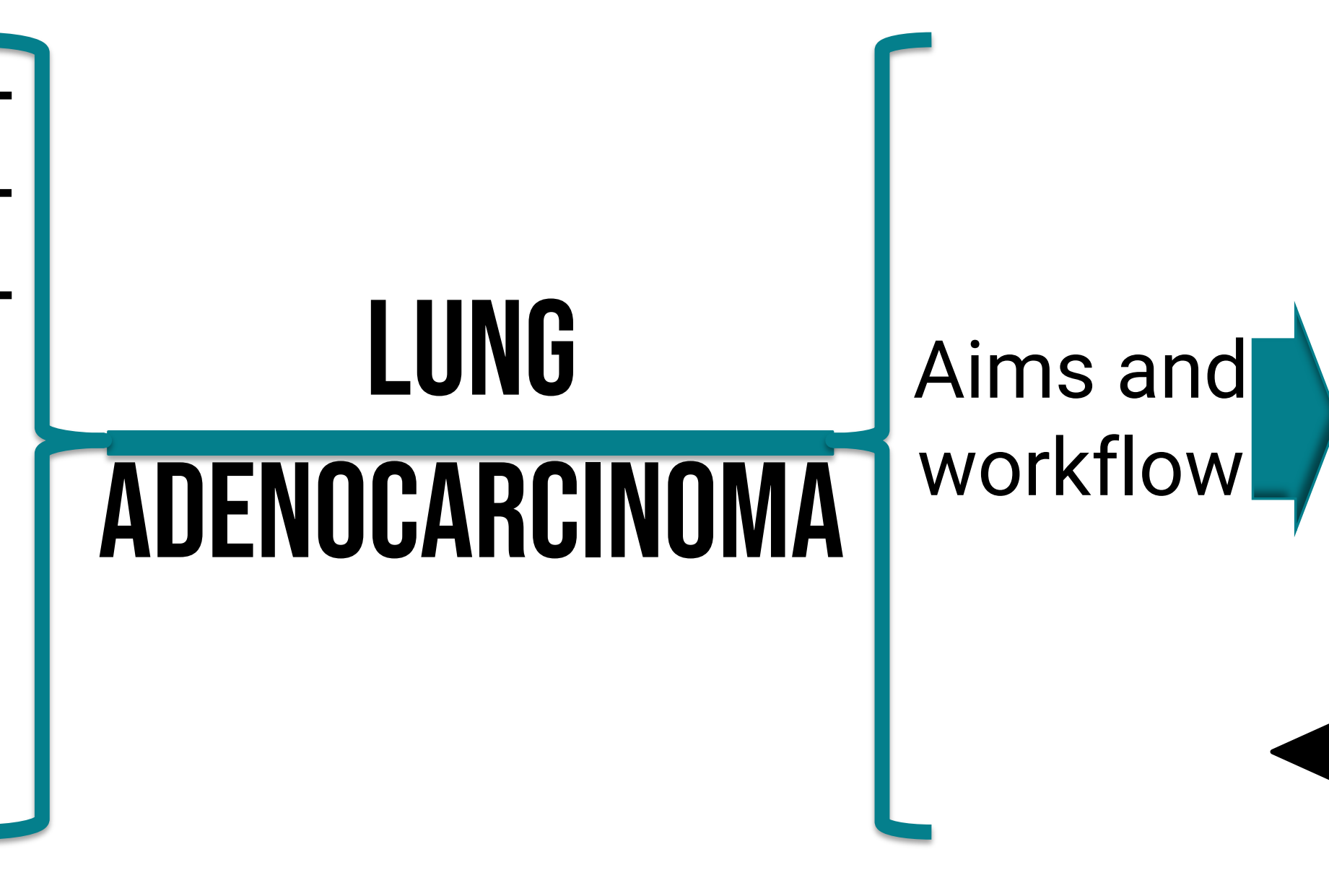

But... ARID1A is not what it seems

\begin{tabular}{|c|c|c|c|}
\hline & Oncogene & Tumor suppressor & Context \\
\hline 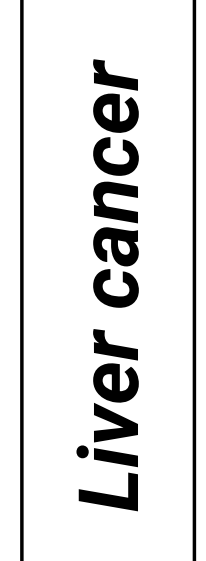 & $\begin{array}{c}\text { Arid1a inactivation } \\
\text { delays tumor onset } \\
\text { (in tumor initiation } \\
\text { contexts) }\end{array}$ & $\begin{array}{l}\text { Arid1a inactivation } \\
\text { accelerates tumor } \\
\text { progression (in } \\
\text { tumorigenic } \\
\text { contexts) }\end{array}$ & 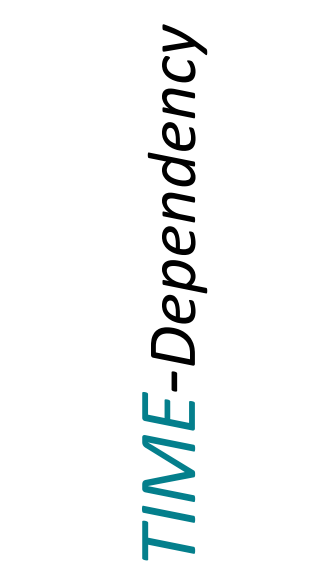 \\
\hline 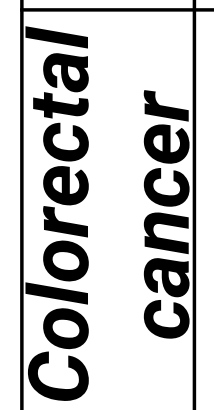 & $\begin{array}{l}\text { Arid1a inactivation } \\
\text { blocks cancer in } \\
\text { Apc-mutants }{ }^{5}\end{array}$ & $\begin{array}{c}\text { Arid1a inactivation } \\
\text { drives cancer in MSI } \\
\text { contexts }\end{array}$ & 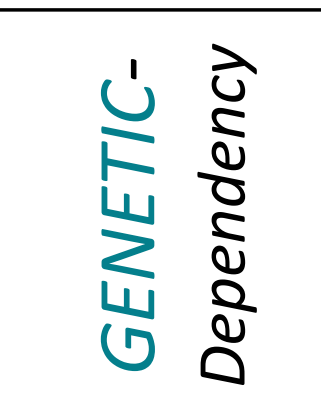 \\
\hline 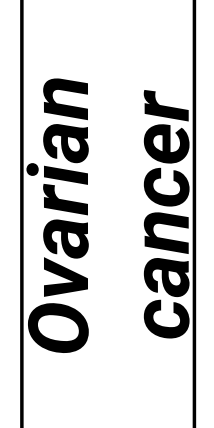 & $\begin{array}{l}\text { Arid1a inactivation } \\
\text { causes } \\
\text { differentiation in } \\
\text { Apc/Pten mutants }\end{array}$ & $\begin{array}{l}\text { Arid1a inactivation } \\
\text { drives cancer with } \\
\text { Pik3ca mutation }\end{array}$ & 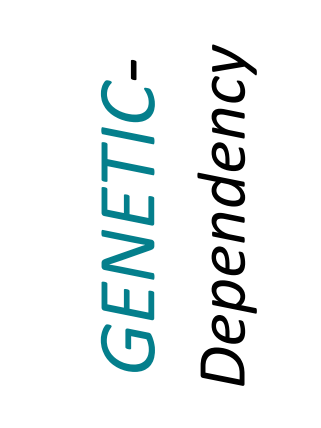 \\
\hline
\end{tabular}

\section{PRELIMINARY RESULTS}

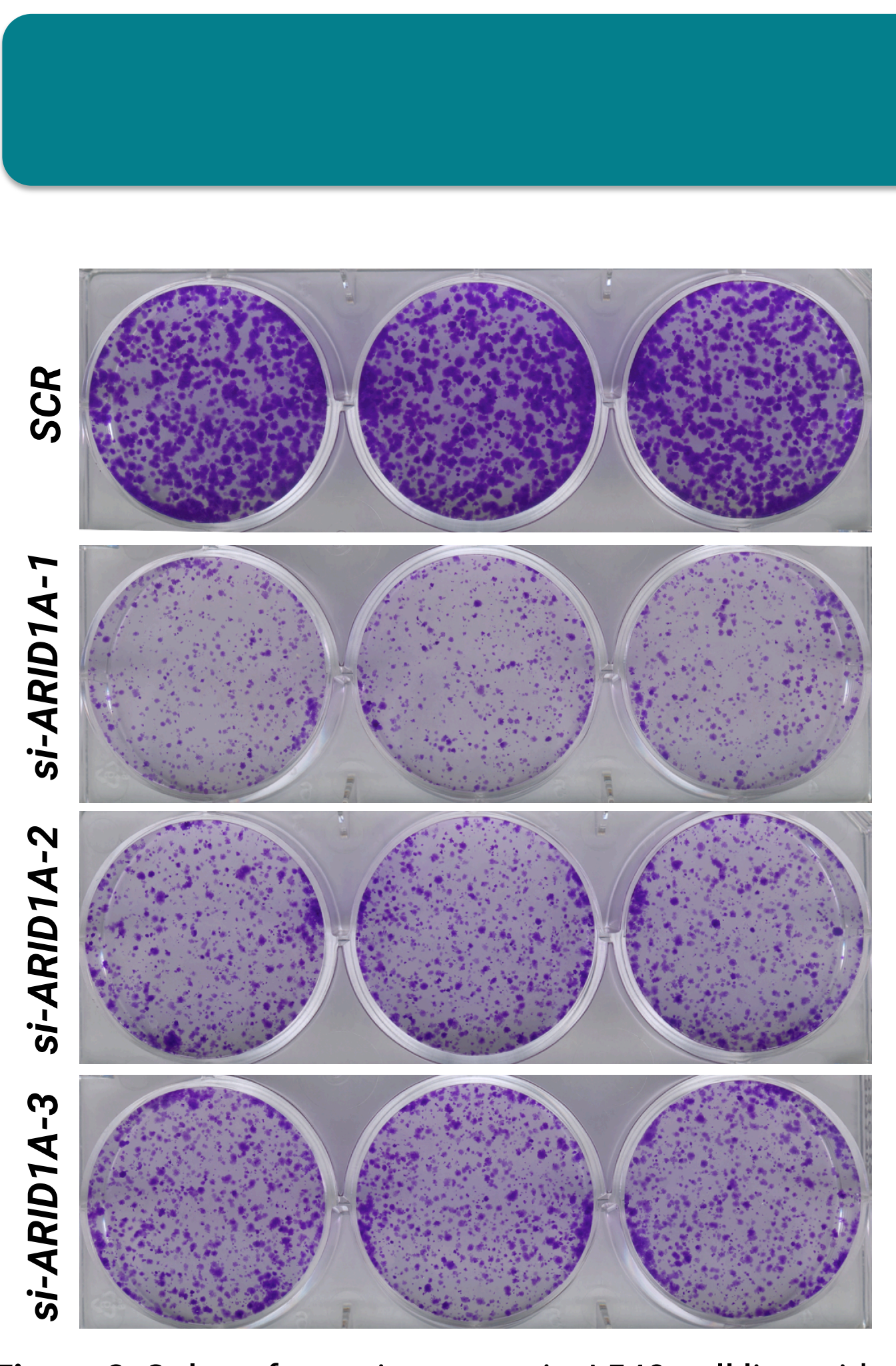

Figure 2: Colony formation assay in A549 cell line with
ARID1A-knockdown after 15 days of transfection.

\section{A549}

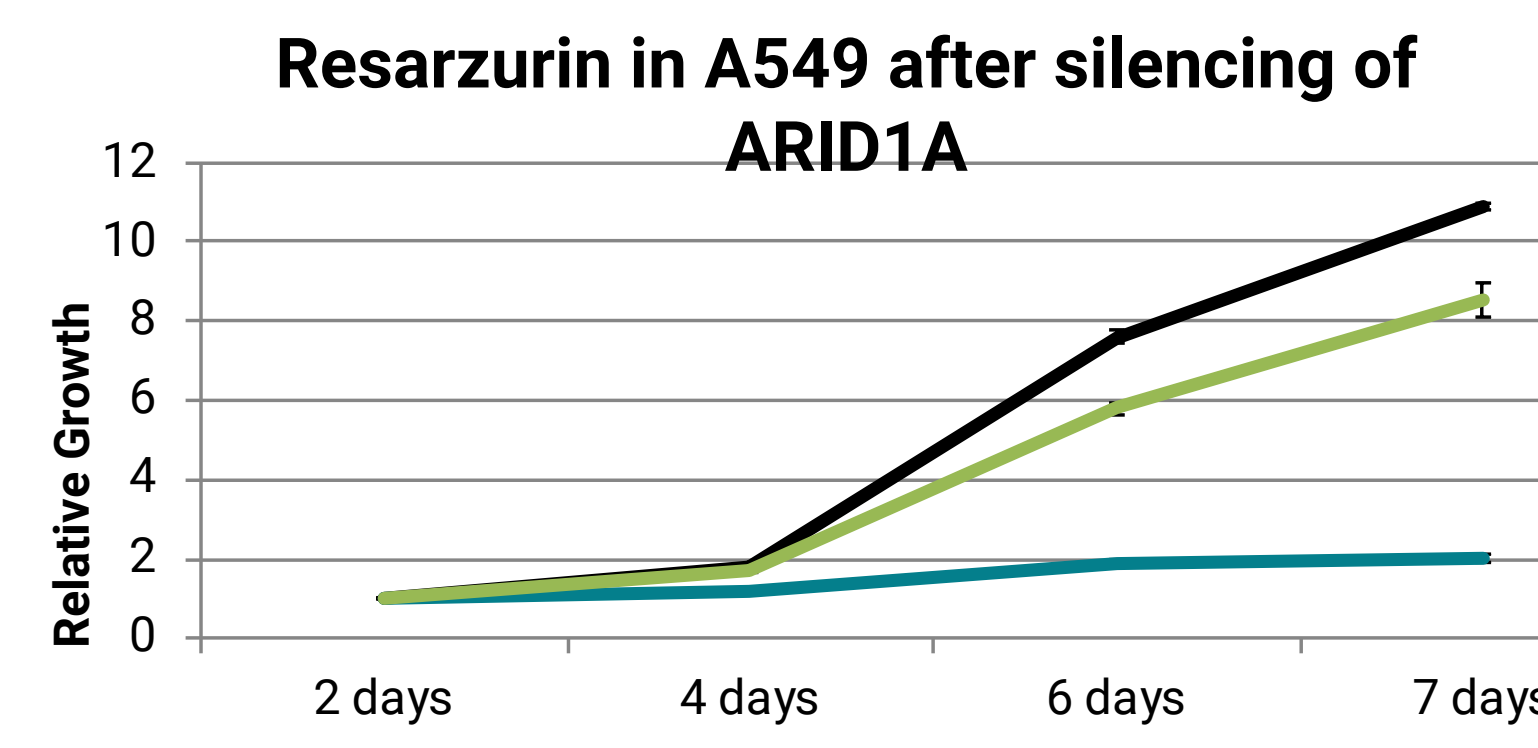

—SCR —SI1-ARID1A - Si3-ARID1A

Figure 3: Cell viability assay in A549 after a single

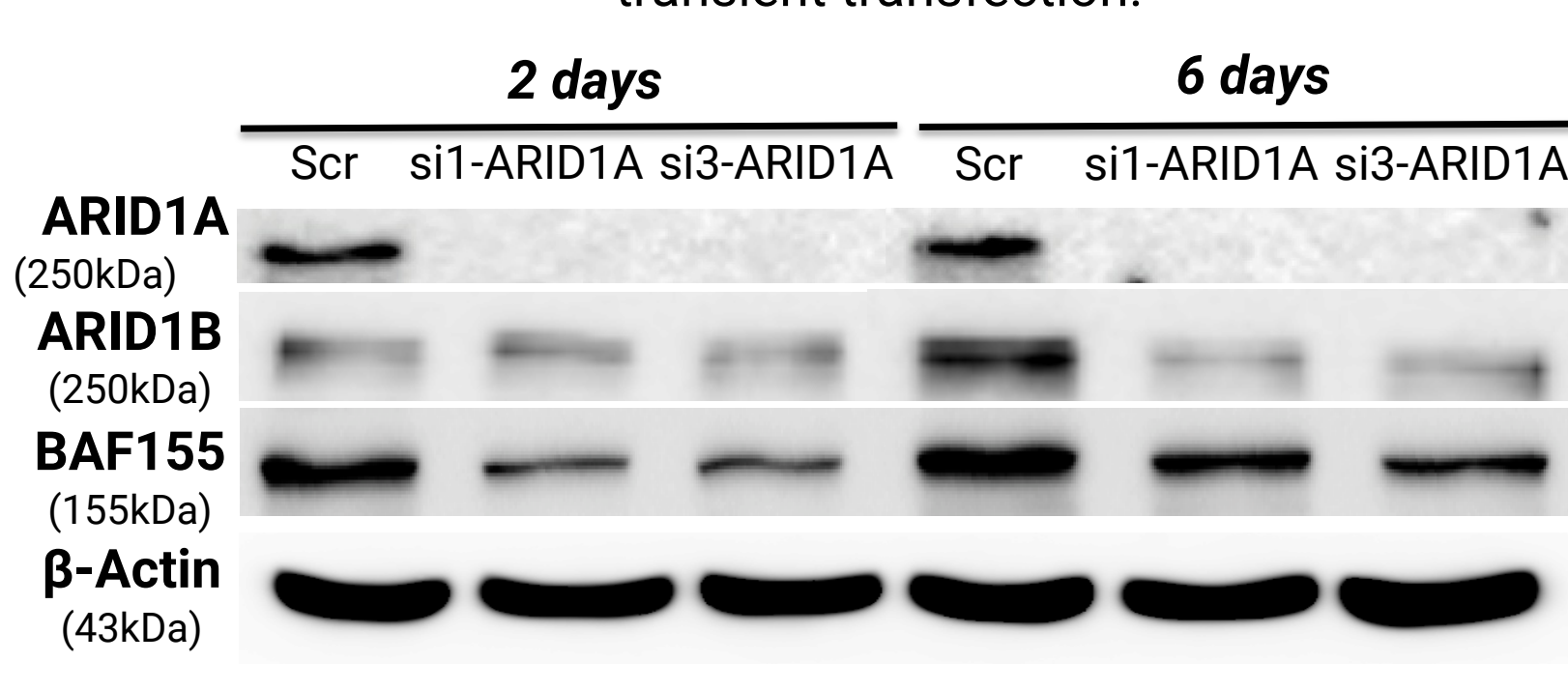

Figure 4: Western Blot of A549 after 2 and 6 days of
ARID1A knockdown.

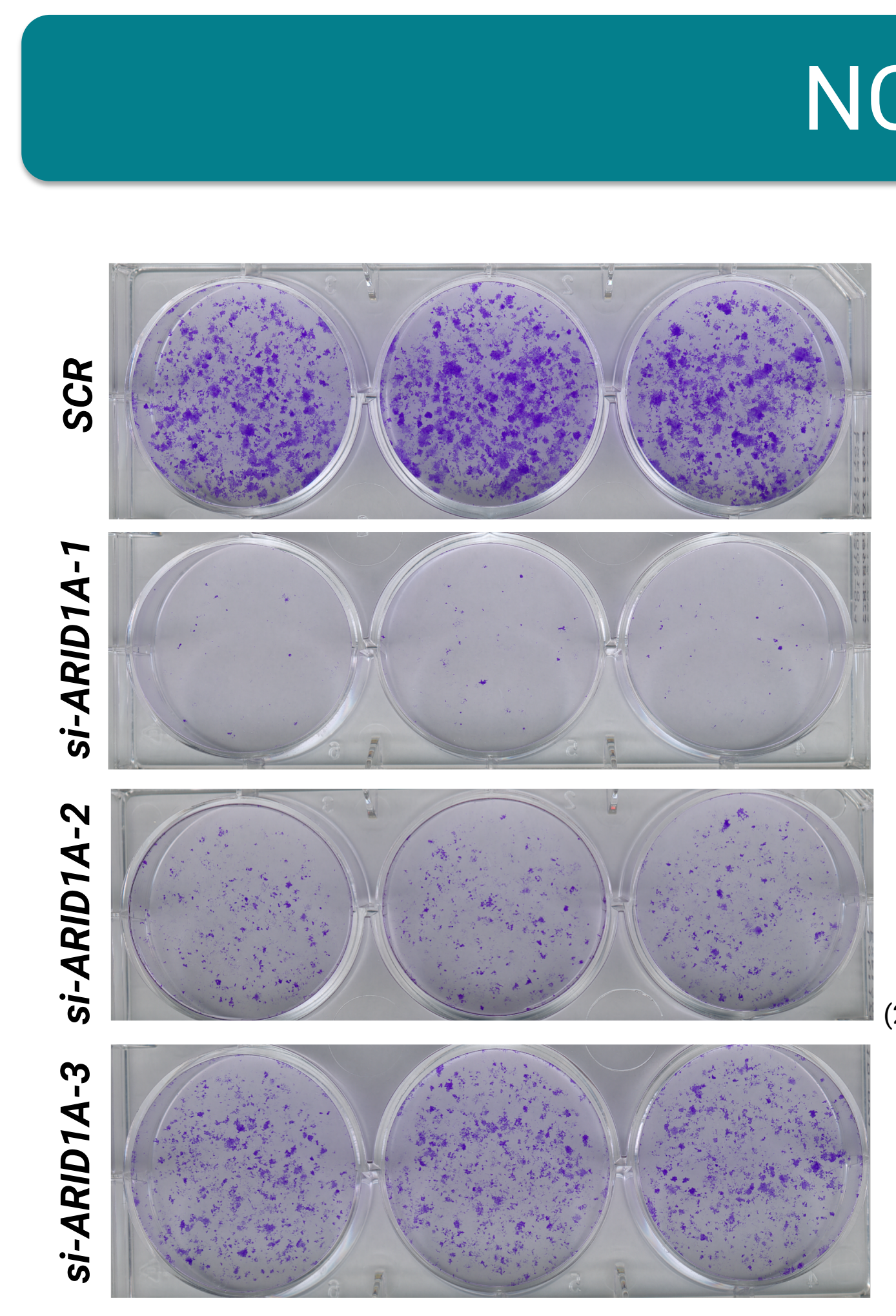

Figure 5: Colony formation assay in $\mathrm{H} 2009$ cell line with

\section{$\mathrm{NCl}-\mathrm{H} 2009$}

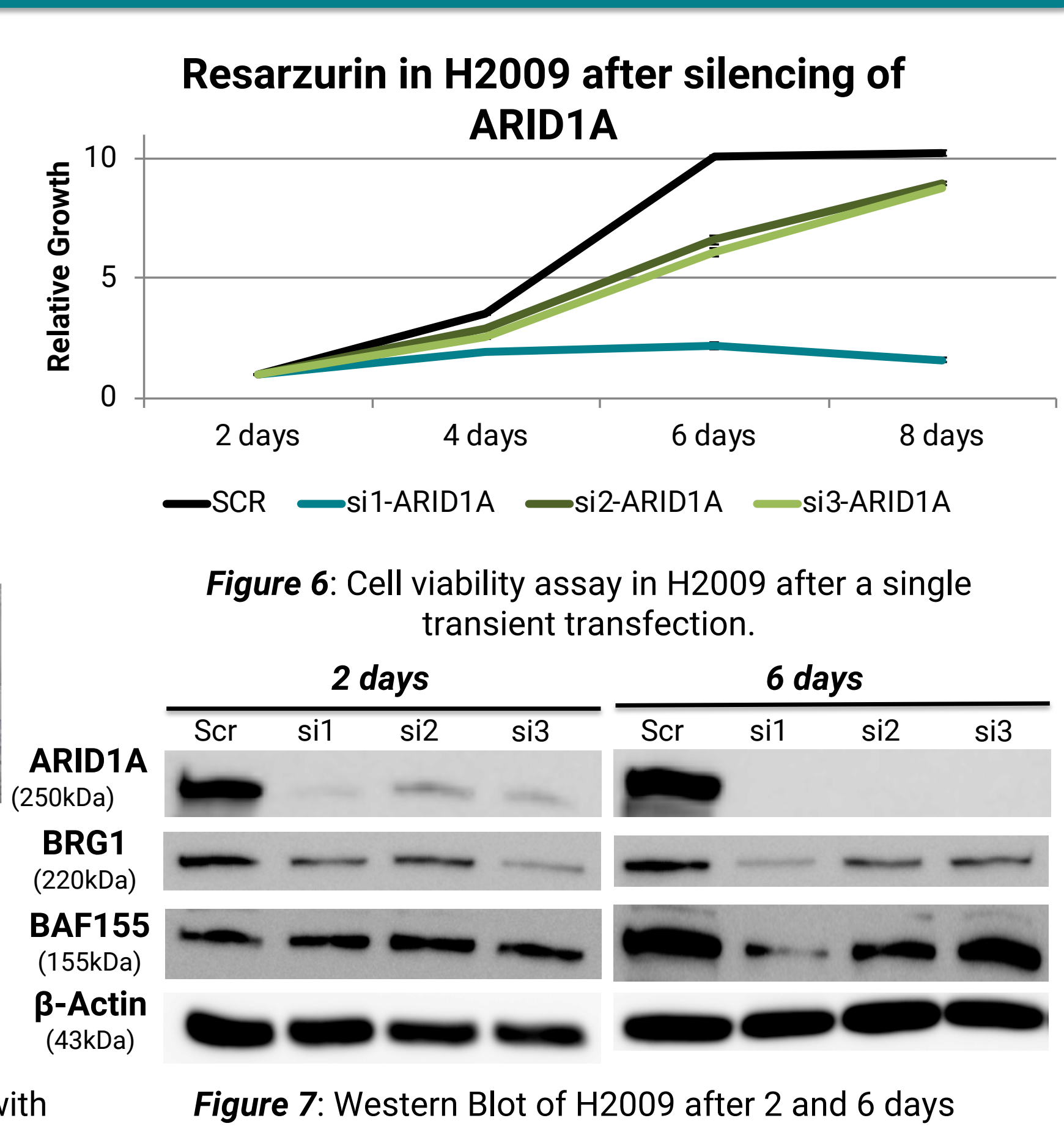

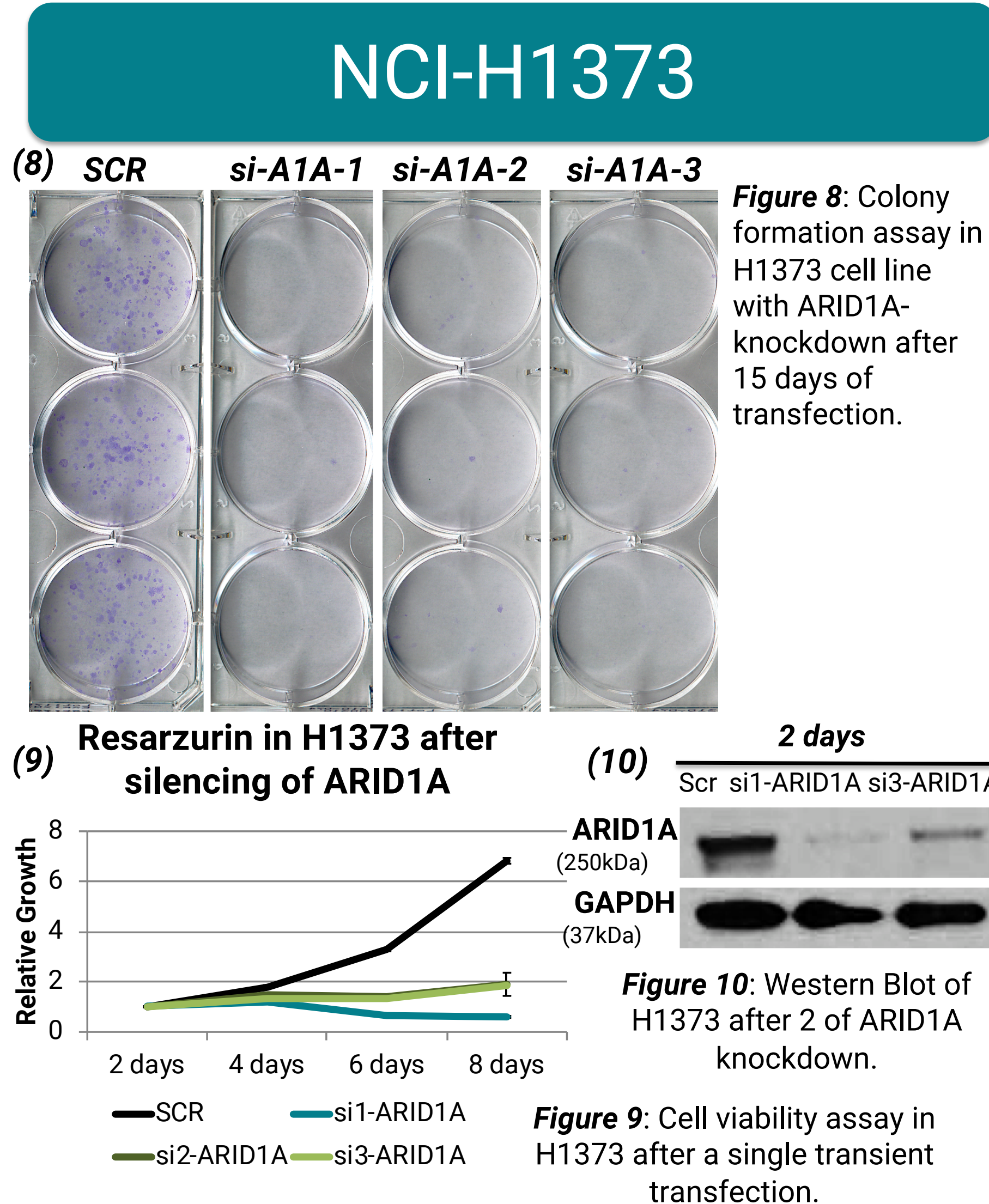

TIME-DEPENDENCY: Normal and tumor lung cell lines (Dual model)
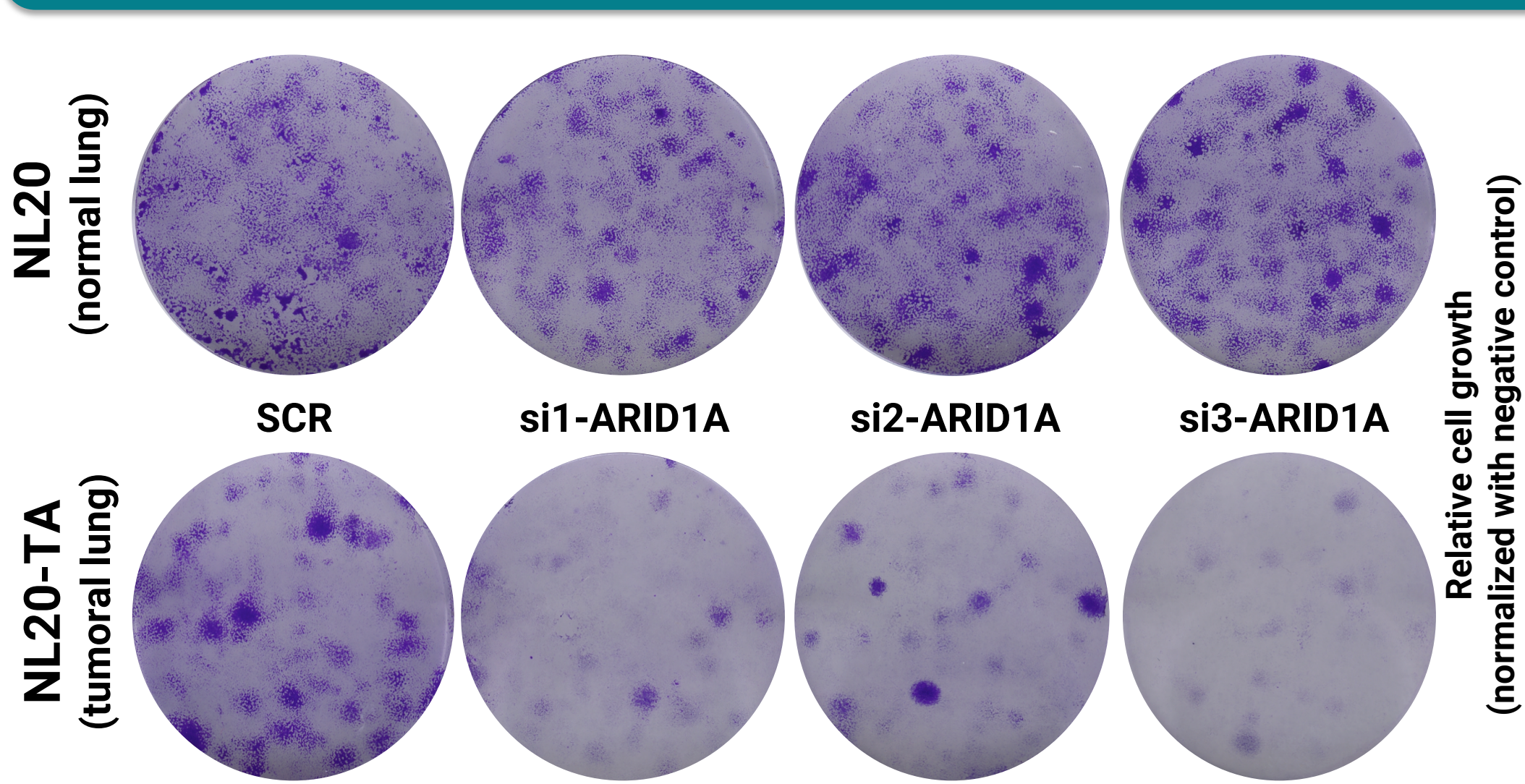

Resarzurin after 6 days of ransfection with siRNA against ARID1A ARID1A-dependency?
Figure CONCLUSIONS AND CURRENT WORKING MODEL

ARID1A has a context-dependent role in lung adenocarcinoma

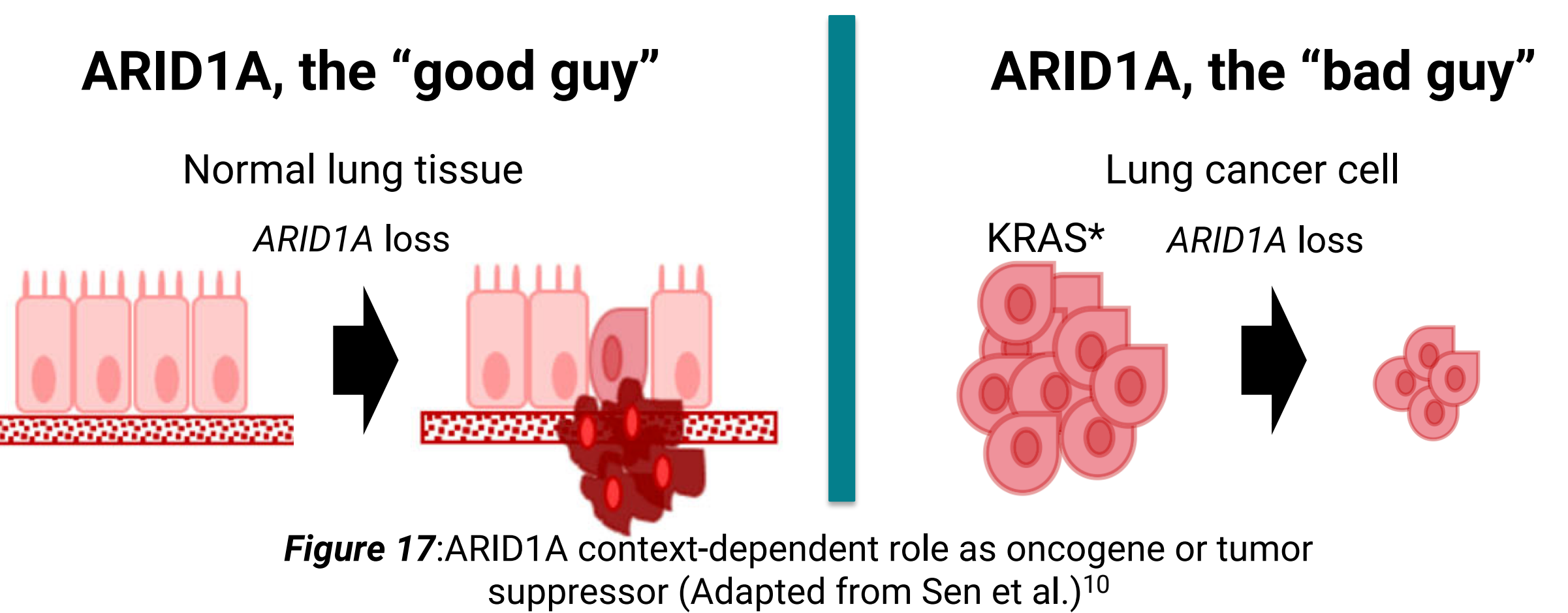

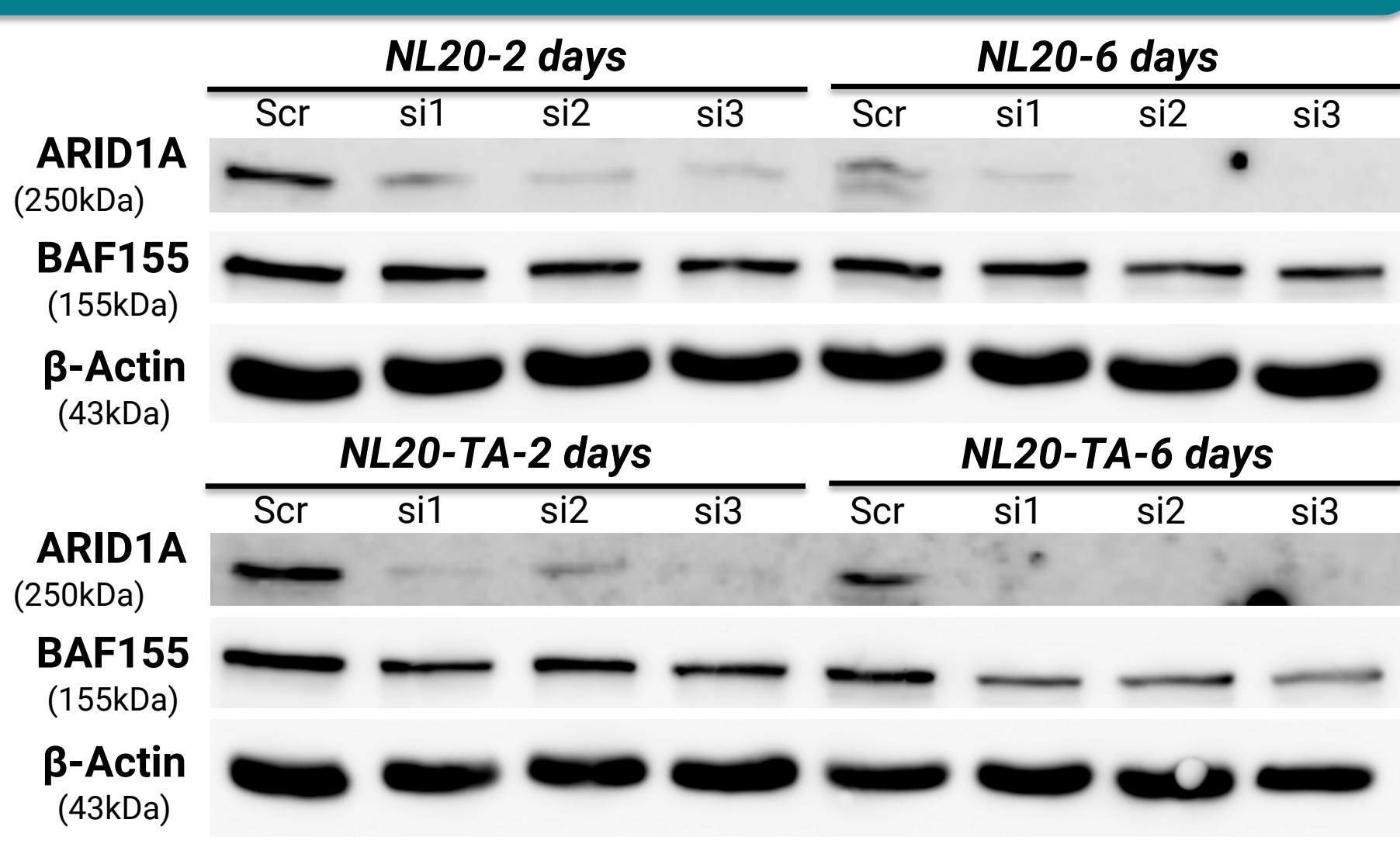

REFERENCES

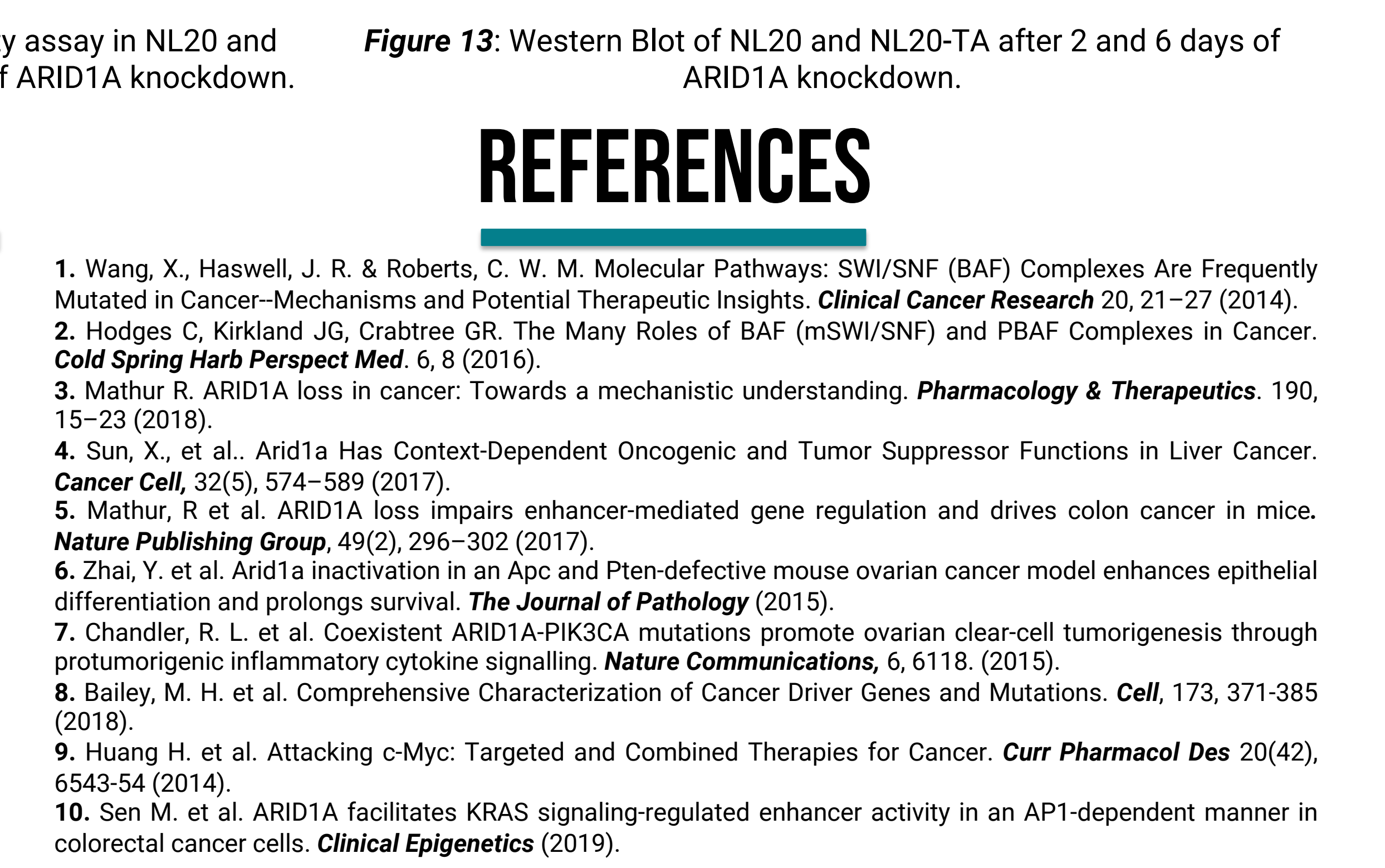

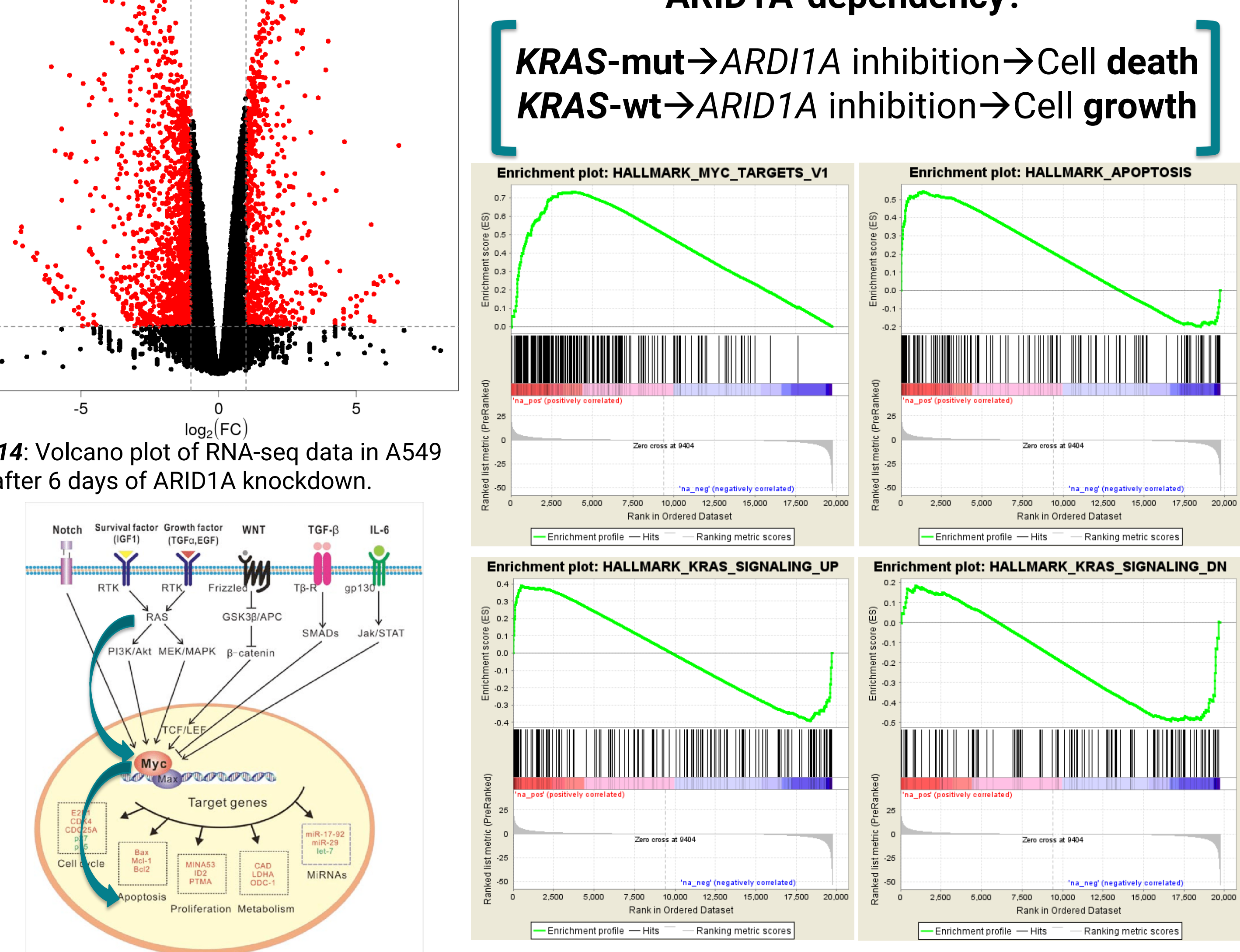

